\title{
Using a logarithmic model to predict functional independence after spinal cord injury: a retrospective study
}

\author{
Yohei Tomioka ${ }^{1} \cdot$ Osamu Uemura ${ }^{1} \cdot$ Ryota Ishii $\mathbb{B}^{2} \cdot$ Meigen Liu $^{3}$ \\ Received: 11 February 2019 / Revised: 2 June 2019 / Accepted: 3 June 2019 / Published online: 25 June 2019 \\ (c) The Author(s), under exclusive licence to International Spinal Cord Society 2019
}

\begin{abstract}
Study design A retrospective cohort study

Objective To establish a logarithmic model to predict functional independence after spinal cord injury.

Setting The National Hospital Organization, Murayama Medical Center, Japan.

Methods Thirty-one adults with a traumatic spinal cord injury (SCI) were enrolled. The Spinal Cord Independence Measure (SCIM) III scores obtained at month 1 and 3 after admission were used to construct a simple logarithmic model to predict SCIM III scores. The validity of the predicted scores was evaluated using a linear mixed model, and agreement between the predicted and measured scores were assessed using the Bland-Altman analysis.

Results In the linear mixed model, the fixed effect slope $[95 \% \mathrm{CI}]$ and the intercept $[95 \% \mathrm{CI}]$ were $1.18[0.78,1.58]$ and -1.75 [ $-10.3,6.83]$, respectively. The scatter plot showed non-linear correlation between the predicted and actual SCIM III scores. This non-linearity became inconspicuous when Sphincter Management scores were omitted. The fixed effect slope and the intercept were $1.12[0.89,1.36]$ and $-1.64[-4.95,1.68]$, respectively. A significant fixed or proportional bias was not identified on the Bland-Altman analysis of the total SCIM III score, with most scores lying between an upper limit of +15.3 and a lower limit of -19.3 .

Conclusion The logarithmic model provided an accurate prediction of the functional independence score of individuals with SCI in our cohort which included various neurological levels and severity of the injury. Along with its simplicity, our prediction model could be useful in daily practice.
\end{abstract}

\section{Introduction}

The efficacy of rehabilitation can be defined from various points of view. In the context of economics, length of stay (LOS) is one of the most important outcomes. In the United States, the overall LOS for rehabilitation after spinal cord

Supplementary information The online version of this article (https:// doi.org/10.1038/s41393-019-0315-z) contains supplementary material, which is available to authorized users.

Osamu Uemura

tbonezjp@yahoo.co.jp

1 Department of Rehabilitation Medicine, National Hospital Organization Murayama Medical Center, Tokyo, Japan

2 Biostatistics Unit, Clinical and Translational Research Center, Keio University Hospital, Tokyo, Japan

3 Department of Rehabilitation Medicine, Keio University School of Medicine, Tokyo, Japan injury (SCI) has dramatically decreased since the early 1970s, with an overall decline from 98 days, on average, in the 1970s, to 34 days in 2018 [1]. However, it is important to note that LOS is not only determined by the recovery of functional independence with rehabilitation. In fact, although a decrease in LOS might be indicative of improved efficiency, across sites, differences in LOS may reflect differences in the rehabilitation process and differences in the criteria for discharge [2]. Shorter LOS, in some cases, might even lead to undesired outcomes, such as a higher rate of rehospitalization and discharge to more restrictive environments [3]. Considering the positive effect of a longer LOS on functional achievements [4] and the economic burden of longer LOS, there would be interest in determining the appropriate LOS to maximize functional achievements, while lowering the risk of adverse outcomes after discharge. Determination of the ideal LOS rests on our ability to predict functional outcome after an injury.

Of the various scales currently available to assess functional outcomes after neurological diseases and injuries, the 
Barthel Index and the Functional Independence Measure (FIM) are the most frequently used, especially in stroke rehabilitation [5]. However, these assessments of functional independence do have shortcomings when used for individuals with a traumatic SCI, lacking items to assess breathing ability and detailed evaluation of excretion, mobility, and transfers. The Quadriplegia Index of Function (QIF) $[6,7]$, the Spinal Cord Injury Functional Ambulation Inventory $[8,9]$, and the Spinal Cord Independence Measure (SCIM) were developed specifically for individuals with SCI, being more specific and sensitive for assessment of function in those with SCI than more generic assessments [10]. The QIF was designed specifically for individuals with quadriplegia and, as such, is not fully applicable for those with a paraplegia, while the Spinal Cord Injury Functional Ambulation Inventory only provides an assessment of walking capacity, without considering activities of daily living (ADLs). The SCIM consists of three major domains (self-care, respiration and sphincter management, and mobility), and it is shown to be sensitive and reliable in addressing global disability associated with SCI [11]. Therefore, the SCIM is considered the most appropriate assessment of functional ADLs for individuals with a SCI [12]. To date, however, the time course of change in SCIM scores after a SCI has not been predicted.

In contrast, in the field of stroke rehabilitation, simple logarithmic curves, derived from two adjacent FIM scores in the early stage of rehabilitation, have been shown to neatly trace the changes in measured FIM scores [13]. We hypothesized that changes in SCIM scores would also fit a simple logarithmic curve, as shown for functional recovery after a stroke. Therefore, our aim in this study was to compare predicted SCIM scores, using a logarithmic model, to that of measured SCIM scores in order to evaluate our hypothesis.

\section{Methods}

\section{Study design}

This is a retrospective cohort study.

\section{Participants}

Eligible individuals were those with a traumatic SCI who were admitted to Murayama Medical Center for rehabilitation, between April 2016 and March 2018. The inclusion criteria were as follows: at least four completed functional assessments using the SCIM version III (SCIM III); age $>20$ years; and absence of any medical health issue that could interfere with the rehabilitation, such as recent orthopedic surgery, and presence of decubitus ulcers, deep venous thrombosis, ectopic ossification, and/ or shoulder pain.

\section{Procedures}

The SCIM III was completed by experienced nurses, on a monthly basis, and data obtained from all participants were included in our analysis. We also collected participants' age, sex, level of injury, and American Spinal Injury Association Impairment Scale (AIS), from the medical records, as background information.

\section{Logarithmic model for the prediction of SCIM III score}

Logarithmic equations for the prediction were determined for each participant uniquely. The independent variable in the model was "days from the onset of injury," as previously reported [13]. Because using scores from the first two assessment points yielded poor prediction (see Discussion), we used the scores of the first and third assessment points for references (Day A and Day B, respectively, indicating the days from the injury). The equation is determined as it passes across the two coordinates (Day A, SCIM (Day A)) and (Day B, SCIM (Day B)). Coefficient $\beta_{\mathrm{i}}$ was calculated by the increase in SCIM III score from Day A to Day B $\left(\Delta\right.$ SCIM), as follows: $\beta_{i}=\Delta$ SCIM $[\ln$ (Day B/ Day A) $]^{-1}$. The predicted SCIM at Day "X", the day of interest, was then calculated as follows: predicted SCIM $=$ $\operatorname{SCIM}($ Day $\mathrm{A})+\beta_{\mathrm{i}} \ln ($ Day X/Day A).

\section{Evaluation of the model fit}

The validity of the logarithmic model was analyzed as follows. We used SCIM III scores of the fourth and subsequent assessment points. Since our data were derived from each participant's repeated measures, we examined the relationship between the predicted and actual SCIM III scores using a linear mixed model [14]. A linear mixed model is used for analyzing multilevel, longitudinal, and non-independent data. The basis of this model is the assumption that the slope and the intercept of the regression equation are determined by the fixed effect and the random effect in each participant. From this assumption, it can express the tendency of the whole data, taking into account the influence of repeated measurement in each participant. We calculated the fixed effect and the random effect of the linear mixed model and subsequently plotted the scattered points. To investigate precisely, both SCIM III scores with and without Sphincter Management items were analyzed. Agreement between the predicted and actual SCIM III total scores (with Sphincter Management items) was analyzed using the Bland-Altman analysis [15], in which the 
difference between both scores was plotted against their means. $\mathrm{P}$ values were considered significant at a level of 0.05. All statistical analyses were performed using IBM SPSS Statistics for Macintosh (version 24.0; IBM Corp., Armonk, New York, USA) and R version 3.5.1 [16].

\section{Results}

Thirty-one individuals, 27 men and 4 women, fulfilled the inclusion criteria. Characteristics of our study group are shown in Table 1, with relevant features summarized as follows: mean (standard deviation, SD) age of 59.0 (19.2) years; days from onset of injury to admission of 45.2 (60.8) days; and days from admission to the first (Day A) and third (Day B) SCIM III assessment of 69.8 (55.6) days and 123.4 (58.2) days, respectively.

Figures 1 and 2 show chronological changes of the predicted and actual SCIM III total scores (with Sphincter Management items) in each participant. In most cases, the pattern of change in the predicted SCIM III scores was quite similar with that of the actual SCIM III scores. In some cases, however, sudden drastic increase in the measured SCIM III scores was observed in participant 2, 10, 11, 20, 21, 22, 28, and 31. In all cases, score changes in the Sphincter Management items account for this drastic increase (data not shown).

Then, we examined the relationship between the predicted and actual total SCIM III scores. In the linear mixed model, the slope $[95 \% \mathrm{CI}]$ and intercept $[95 \% \mathrm{CI}]$ of the fixed effect were $1.18[0.78,1.58]$ and $-1.75[-10.3,6.83]$, respectively, in the total SCIM III score analysis (Fig. 3). The estimated variance $[95 \% \mathrm{CI}]$ of the random effect was $0.71[0.37,1.36]$ for the slope, 397.0 [205.0, 768.6] for the intercept, and 8.1 $[6.3,10.3]$ for the residual. However, the scatter plot showed non-linear correlation, i.e., individuals with high and low SCIM III scores were overestimated and those with intermediate scores were underestimated (Fig. 3). To overcome this non-linearity, we subsequently analyzed the relationship between the predicted and actual SCIM scores without Sphincter Management items. In the scatter plot, non-linearity became inconspicuous (Fig. 4). In the linear mixed model, the slope $[95 \% \mathrm{CI}]$ and intercept $[95 \% \mathrm{CI}]$ of the fixed effect were $1.12[0.89,1.36]$ and $-1.64[-4.95,1.68]$ (Fig. 4), respectively. The estimated variance $[95 \% \mathrm{CI}]$ of the random effect was $0.21[0.09,0.46]$ for the slope, 47.6 [20.8, 109.1] for the intercept, and 3.07 [2.37, 3.97] for the residual. On the Bland-Altman analysis, there was no significant proportional bias $(-0.037 ; 95 \%$ CI $[-0.094,0.021])$ or fixed bias $(-0.84$; $95 \%$ CI $[-3.03,1.35])$ between the difference and average of the actual and predicted total SCIM scores. Limits of agreement were -19.3 and +15.3 at the lower and the upper limits, respectively (Fig. 5).

\section{Discussion}

We introduced a new method to predict the functional outcome at any time points after a SCI. The logarithmic model originally developed in stroke nicely fits the time course of SCIM III changes after SCI. Indeed, statistical analysis revealed an insignificant difference between the predicted and measured SCIM III scores. This is not surprising because, as previously shown in individuals with a SCI [17], changes in functional score (SCIM in this case) after SCI were likely to trace logarithmic curves regardless of AIS grades. Simple as it is, our model could be useful in daily practice.

\section{Merit of using logarithmic model}

The strength of our logarithmic model is that it can predict the SCIM III scores at arbitrary time points in a variety of levels and/or types of injury. Prognostication at the early stage after injury is very important for both the individual with a SCI and health care providers who are responsible to set the outcome and to effectively manage the rehabilitation process toward that goal. A great deal of work has been done on this issue [18-23]. Predicting ADL outcome after a SCI is complicated, as functional outcomes after rehabilitation are strongly influenced by the AIS grade [20] and the neurological level, which significantly affects the SCIM III score [19]. To avoid this issue, previous researchers have focused on the outcome for specific ADL items at a fixed time point, obtaining quite accurate prediction models [24, 25]. However, at the rehabilitation stage, as individuals with a SCI must learn new strategies to complete many ADL items, a step-by-step index to the next level of ADLs is necessary.

Our logarithmic model allows us to predict SCIM III changes at any time points. However, utilizing total SCIM III scores as indicators of discharge time might not be straightforward because of the following reasons. First, the living environment after the discharge varies among individuals so that personalized coordination of the social circumstances, which might take time, is required. Second, the total SCIM III score is solely a summation of each ADL item scores. Different scores in each ADL item could even result in identical total SCIM III scores. Research efforts have been made to elucidate the statistical relationship between each SCIM III item score and total scores [10, Unai and OU, in preparation]. According to these studies, each presumed single ADL item score could be derived from the total SCIM III scores. In combination with these ADL structure analyses, it might be possible to predict the likely functional outcome of any SCIM III item at any time points based on early functional scores. Once the presumptive functional outcome is obtained, environmental coordination 
Table 1 Patient characteristics

\begin{tabular}{|c|c|c|c|c|c|c|c|c|c|}
\hline Case & Age & Gender & Injured level & AIS & Operation & Comorbidity & $\begin{array}{l}\text { First assessment from } \\
\text { injury (Day A) }\end{array}$ & $\begin{array}{l}\text { Third assessment from } \\
\text { injury (Day B) }\end{array}$ & $\begin{array}{l}\text { The number of } \\
\text { assessments }\end{array}$ \\
\hline No.1 & 23 & M & Thoracic & A & + & $\mathrm{MBF}$ & 53 & 115 & 4 \\
\hline No. 2 & 65 & M & Cervical & $\mathrm{C}$ & - & & 51 & 128 & 5 \\
\hline No. 3 & 40 & $\mathrm{~F}$ & Thoracic & A & + & & 162 & 212 & 6 \\
\hline No.4 & 62 & M & Cervical & $\mathrm{C}$ & - & & 21 & 77 & 11 \\
\hline No.5 & 64 & M & Cervical & A & + & OPLL & 95 & 151 & 5 \\
\hline No.6 & 63 & M & Cervical & $\mathrm{C}$ & - & CSM & 23 & 84 & 9 \\
\hline No.7 & 81 & M & Cervical & $\mathrm{D}$ & - & $\begin{array}{l}\text { MBF, OA } \\
\text { of knee }\end{array}$ & 31 & 78 & 17 \\
\hline No. 8 & 69 & M & Cervical & $\mathrm{C}$ & + & Dementia & 44 & 93 & 8 \\
\hline No.9 & 67 & M & Cervical & $\mathrm{C}$ & + & $\mathrm{CDH}$ & 61 & 129 & 8 \\
\hline No.10 & 29 & M & Thoracic & A & + & & 50 & 120 & 12 \\
\hline No.11 & 76 & M & Cervical & $\mathrm{C}$ & + & & 26 & 87 & 9 \\
\hline No.12 & 71 & $\mathrm{~F}$ & Cervical & A & - & AS & 49 & 117 & 9 \\
\hline No.13 & 27 & $\mathrm{~F}$ & Lumbar & $\mathrm{C}$ & + & $\mathrm{MBF}$ & 222 & 290 & 6 \\
\hline No.14 & 84 & M & Cervical & $\mathrm{C}$ & + & & 72 & 118 & 9 \\
\hline No.15 & 78 & M & Cervical & $\mathrm{C}$ & - & OPLL & 42 & 81 & 12 \\
\hline No.16 & 75 & $\mathrm{M}$ & Cervical & $\mathrm{D}$ & - & & 59 & 101 & 7 \\
\hline No.17 & 72 & M & Cervical & $\mathrm{D}$ & - & $\mathrm{CSM}$ & 46 & 107 & 8 \\
\hline No.18 & 74 & M & Cervical & $\mathrm{C}$ & - & & 68 & 127 & 13 \\
\hline No.19 & 26 & M & Lumbar & $\mathrm{C}$ & + & & 33 & 83 & 13 \\
\hline No.20 & 64 & $\mathrm{~F}$ & Cervical & $\mathrm{D}$ & + & $\begin{array}{l}\text { CSM, } \\
\text { Meningioma }\end{array}$ & 59 & 119 & 8 \\
\hline No. 21 & 58 & M & Cervical & $\mathrm{C}$ & - & LSCS & 66 & 92 & 20 \\
\hline No.22 & 83 & M & Cervical & $\mathrm{D}$ & - & & 48 & 91 & 8 \\
\hline No.23 & 59 & M & Cervical & $\mathrm{D}$ & + & DISH & 128 & 165 & 11 \\
\hline No.24 & 50 & M & Cervical & $\mathrm{D}$ & - & $\mathrm{CRH}$ & 260 & 318 & 10 \\
\hline No. 25 & 47 & M & Cervical & $\mathrm{C}$ & + & & 15 & 71 & 8 \\
\hline No.26 & 53 & M & Cervical & $\mathrm{C}$ & + & CSM, LSCS & 96 & 156 & 9 \\
\hline No. 27 & 73 & M & Cervical & $\mathrm{C}$ & + & & 67 & 122 & 10 \\
\hline No.28 & 34 & M & Cervical & $\mathrm{C}$ & + & & 18 & 53 & 11 \\
\hline No.29 & 20 & M & Cervical & A & + & & 47 & 85 & 8 \\
\hline No.30 & 67 & M & Cervical & $\mathrm{D}$ & + & OPLL & 85 & 147 & 5 \\
\hline No.31 & 76 & M & Cervical & $\mathrm{B}$ & - & & 66 & 107 & 5 \\
\hline
\end{tabular}

AIS American spinal injury association Impairment Scale,

$M B F$ multiple bone fracture, $O P L L$ ossification of posterior longitudinal ligament, $C S M$ cervical spondyloticmyelopathy, $O A$ osteoarthritis, $C D H$ cervical disc hernia,

$A S$ ankylopoietic spondylarthritis, $L S C S$ lumbar spinal canal stenosis, $D I S H$ diffuse idiopathic skeletal hyperostosis, $C R H$ craniotomy for removal of hematoma

will be easy to plan. With this information, LOS would be determined. The appropriateness of LOS should be examined after discharge with subjective measures. Future research is necessary.

As previously reported [18-23], early physical assessment can allow prediction of ADL achievement with high accuracy. However, in the absence of a nation-wide database for SCI in Japan, it is sometimes quite difficult to obtain sufficient medical information when individuals with a SCI are transferred to rehabilitation centers. Our model is simple, using SCIM III data obtained from two time points, at about a 1-month interval. Despite its simplicity, the model allows precise prediction of functional outcome after a SCI with various neurological states, and the accuracy is higher than the multiple linear regression model reported previously [22]. Taken together, our logarithmic model could provide a basis to guide rehabilitation after a SCI. 


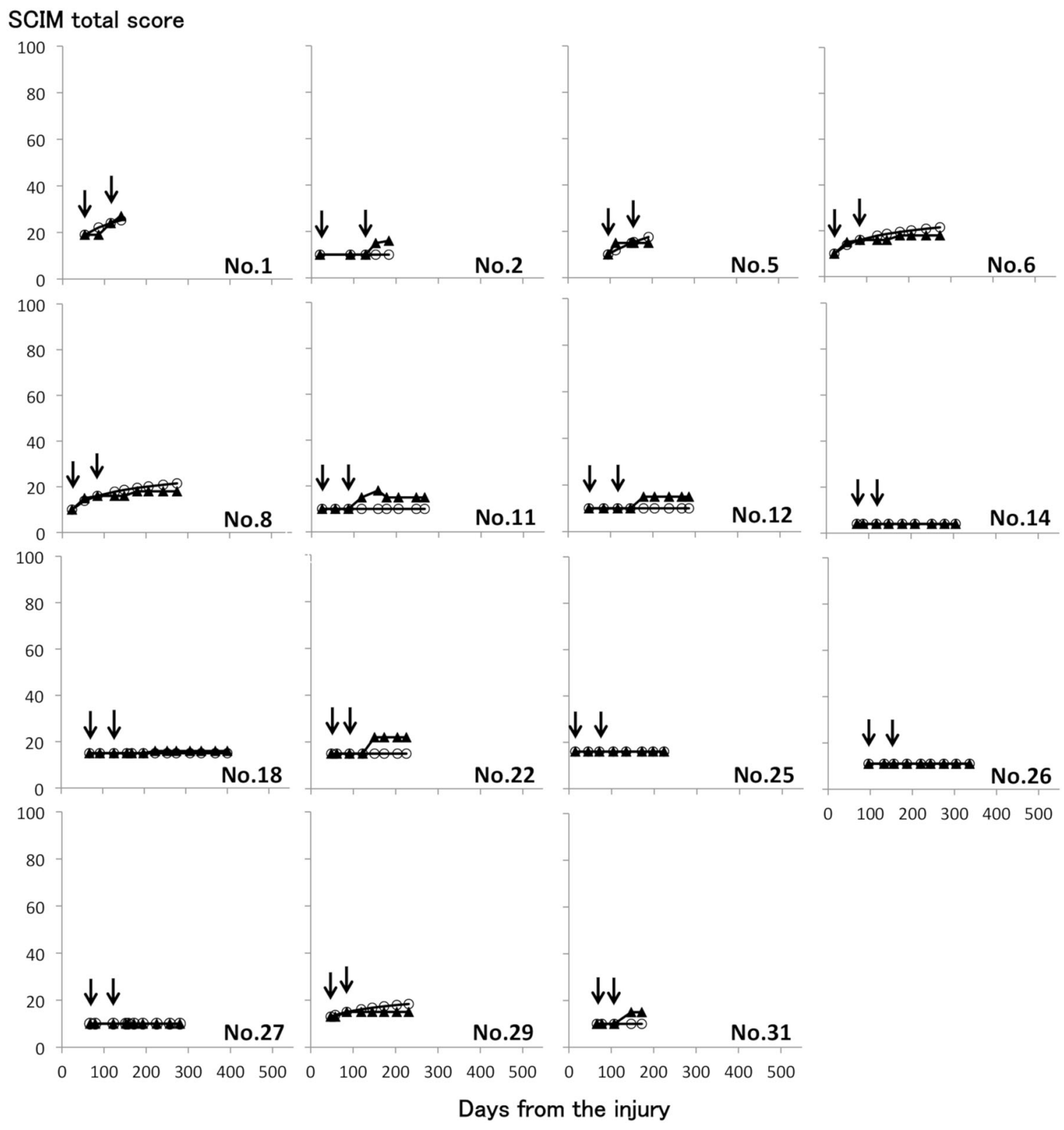

Fig. 1 SCIM total actual scores with Sphincter Management items (ム) are plotted parallel with predicted scores (O) against the days from the injury. Reference points used for forming prediction logarithmic formula are indicated with the arrow. The number in each graph corresponds to each individual's profile in Table 1. The participants whose score remained under 50 were collected in this figure. SCIM, Spinal Cord Independence Measure

\section{Validity of reference points}

Two FIM scores, obtained at least 14 days apart, are sufficient to predict FIM score at arbitrary time points after stroke using a logarithmic model [9]. When using the SCIM III, however, the interval between time points of assessment should be longer. Specifically, curves based on two SCIM III scores obtained at an interval of about 14 days, which were days between the first and second assessment points, did not yield reliable predictions (data not shown). This is why we increased the interval between SCIM III measures to about 1 month. The SCIM was shown to be more sensitive to changes than the FIM [26]. Thus, the poor predictability using scores obtained at a 14-day interval is not due to the SCIM III itself, but may reflect that functional recovery in individuals with a SCI is not observable on a short time scale. Indeed, Turner-Stokes et al. reported lower gains on the FIM and longer LOS for individuals with a SCI than for those with stroke, in Australia [27]. Similar differences in LOS for SCI and stroke patients were observed 

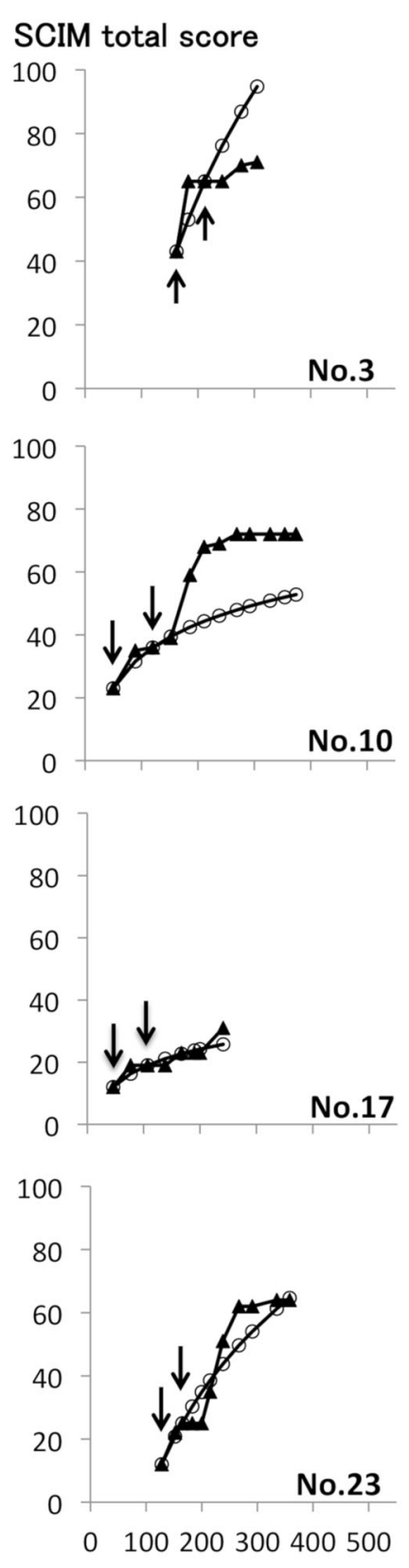
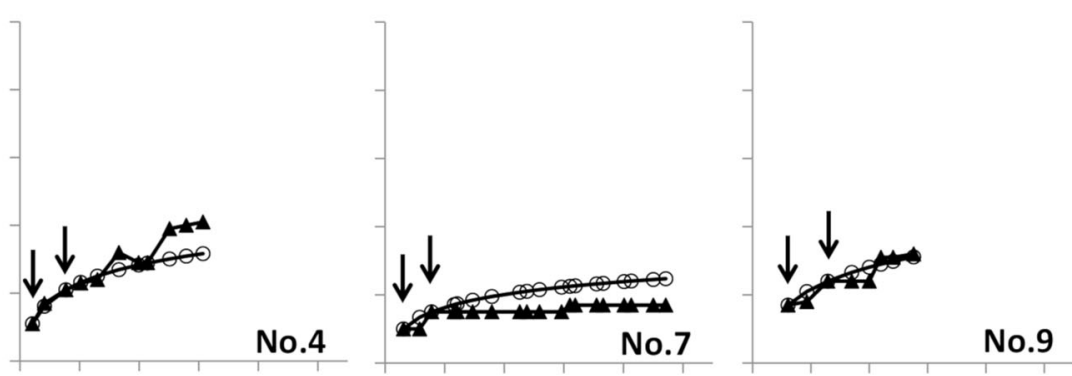

No.9
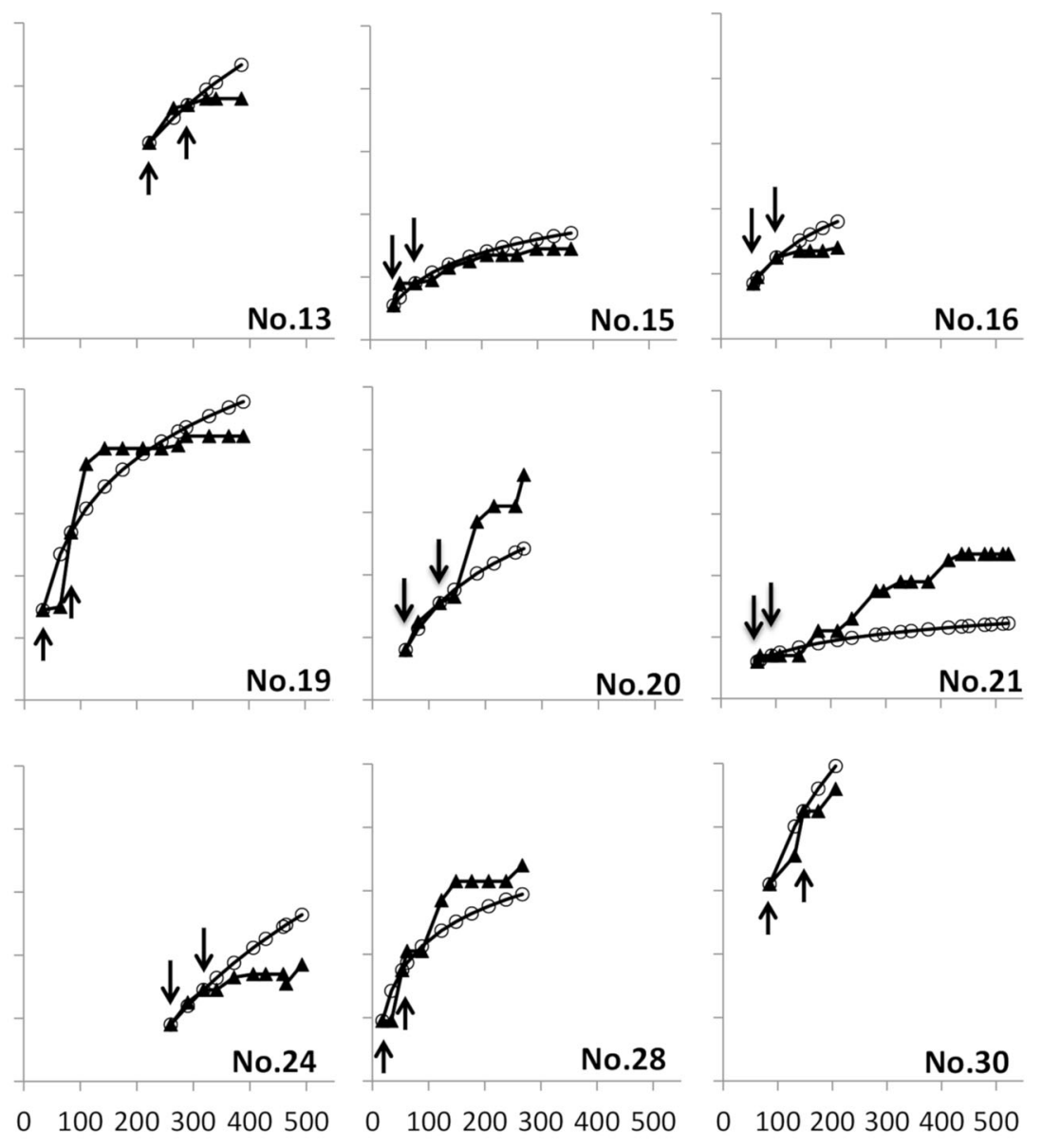

\section{Days from the injury}

Fig. 2 SCIM total actual scores with Sphincter Management items (ム) are plotted parallel with predicted scores (O) against the days from the injury. Reference points used for forming prediction logarithmic formula are indicated with an arrow. The number in each graph

in Korea [28]. The underlying mechanism for this slower, and overall lower, functional improvement for SCI than for stroke remains to be clarified. However, if this slower recovery is SCI-specific, then a more rapid prediction of outcomes using our simple logarithmic model would not be expected. Comorbidities of acute and subacute SCI, such as orthostatic hypotension $(\mathrm{OH})$, can also complicate corresponds to each individual's profile in Table 1. The participants whose score exceeded 50 points are included in this figure. SCIM, Spinal Cord Independence Measure

rehabilitation [29]. As an example, although $\mathrm{OH}$ improved during the first month of rehabilitation after a SCI, OH can persist for years and even worsen with time $[29,30]$. This adaptation period may contribute to the slower rise in the SCIM III score from the first to the second month of rehabilitation. A wide array of physical and pharmacologic treatment options for $\mathrm{OH}$ has been reported, with no 


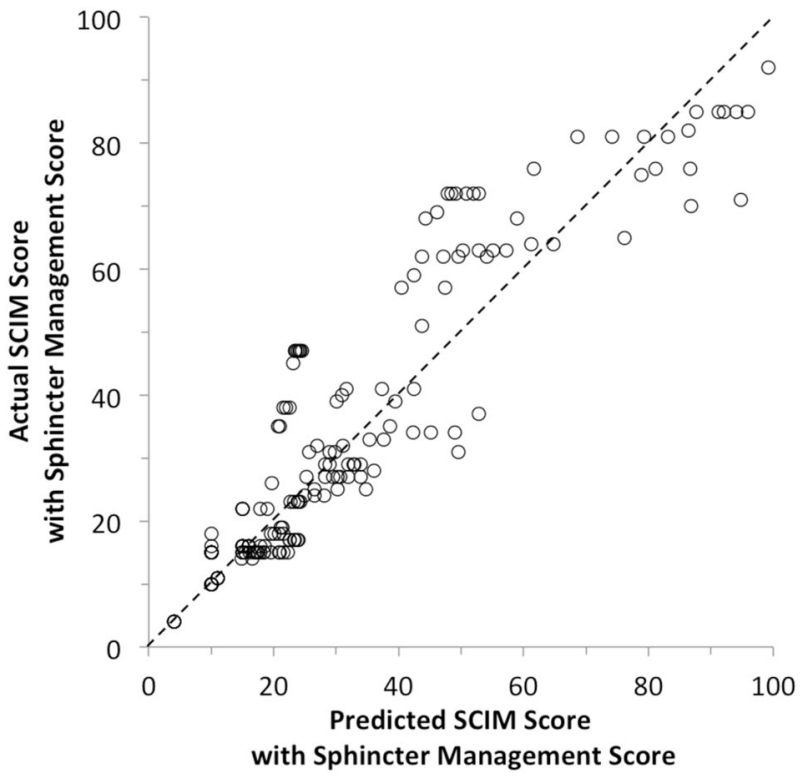

Fig. 3 Correlation between the predicted SCIM total score and the actual total scores. All scores shown are from the fourth or subsequent SCIM assessment. Identity line is drawn in dashed line. SCIM, Spinal Cord Independence Measure

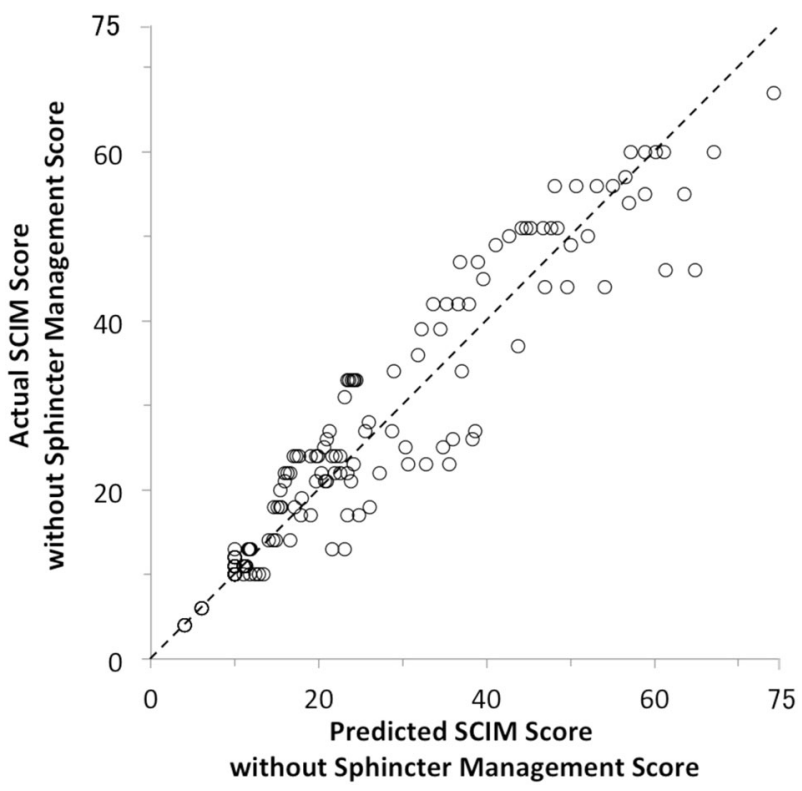

Fig. 4 Correlation between the predicted SCIM score and actual scores without Sphincter Management items. All scores shown are from the fourth or subsequent SCIM assessment. Identity line is drawn in dashed line. SCIM, Spinal Cord Independence Measure

confirmation of their therapeutic effectiveness, with the exception of Functional Electric Stimulation of the legs, which is promising for the treatment of $\mathrm{OH}$ [31]. Early and effective treatment of $\mathrm{OH}$ could support earlier prognostication of functional outcomes.

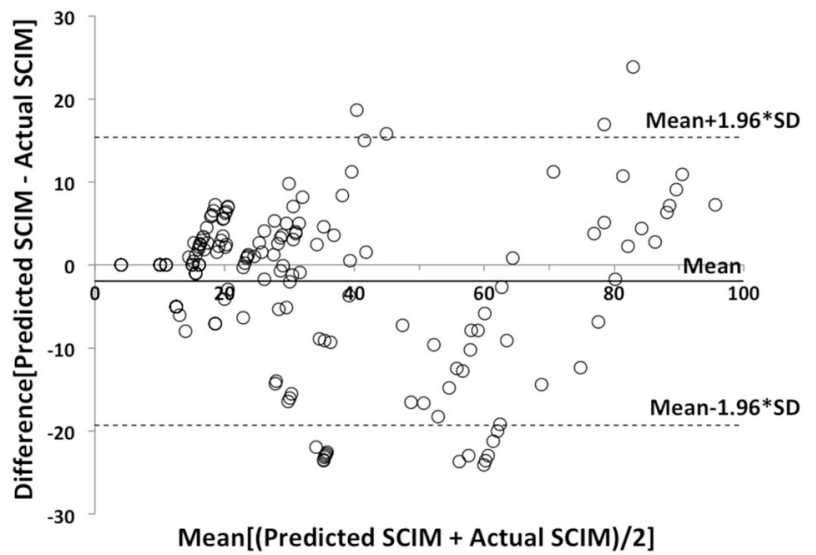

Fig. 5 Bland-Altman plots comparing the mean SCIM total scores (with Sphincter Management items) with the difference between the actual and predicted scores. The middle line represents the mean difference between the predicted and actual scores. The upper and lower lines represent the limits of agreement $( \pm 1.96$ SD). SCIM, Spinal Cord Independence Measure

\section{Characteristic point of the SCIM and limitation of the model}

Although the change in SCIM III scores were characterized, overall, by a logarithmic curve, in some cases, the model underestimated functional recovery. Those whose predicted SCIM III scores were underestimated showed a drastic increase in SCIM III scores after the reference time point, followed by a rather steady progress.

SCIM III is characterized by its unique scoring method. Respiration and Sphincter Management domain, which consists of four items, share a large part of the total SCIM score, that is, a maximum of 40 points of the total of 100 points. Among the items, the highest score of 15 points is allocated to item 6, Sphincter Management-Bladder. As previously reported, the scores of 6,9 , and 13 for this item were nonemergent [10]. Specifically, in the course of either restoring bladder function or learning bladder management methods, a step-wise transition to the next grades might not be observed. Moreover, it is also possible that transition to the next grade can occur more rapidly than expected, such that a monthly assessment would not accurately detect these changes. We must also consider that the residual urine volume may not necessarily change in a time-dependent, step-wise fashion with a change in Sphincter ManagementBladder. As an example, early bladder management training in the early stage of rehabilitation may not be possible due to complications, such as $\mathrm{OH}$ or impairment in finger dexterity, resulting in a sudden improvement in the SCIM III score after the reference point as these complications improve. As shown in the result, the accuracy of our logarithmic model increased by removing the Sphincter Management scores. When dealing this delayed increase in 
the Sphincter Management scores with efforts such as early intervention, more frequent evaluation or revision in scoring system could not be expected, which might be the limitation of the logarithmic model.

The limitations of our study should be acknowledged in the interpretation of results. First, our sample size was relatively small, with all participants recruited from a single spinal cord rehabilitation center in Tokyo. Furthermore, since our hospital does not accept patients with severe respiratory impairment, it is possible that the data used in this study are different from those in other regions in Japan or worldwide. It should also be noted that the epidemiology of SCIs varies by country. As an example, in the recent report from the Japan Labor Health and Safety Organization Rosai Hospital, of the 139 newly registered cases of SCI in their database, in 2016, $60 \%$ were individuals over the age of 60 years, which is reflective of the rapidly aging Japanese population [32]. By comparison, according to a 2000 worldwide survey of SCIs, the average age of injury is in the third decade [33]. Injury types and AIS grades also vary worldwide. In addition, animal experiments suggested gender differences in functional improvement after SCI [34]. Our prediction model uses SCIM III scores from two different time points, that is, the greater the degree of the recovery is observed, the higher the predicted SCIM III score becomes. If this relationship is conserved between male and female sex, it is unlikely that the sex difference influences the prediction model. Because of the sex bias in our participants, we could not exclude the possibility that male and female sexes show different time course of functional recovery after SCI. Thus, caution must be paid when adapting our predictive curves to other regions and/or populations. Lastly, we need to consider that in our study, we used SCIM III data which were obtained between day 0 and day 260 after SCI, Day A, for prediction. For four participants whose transfer to our hospital had been delayed because of their medical conditions, we obtained the first SCIM III scores on day 100 or later post-injury. As the number of individuals with longer-term SCIM III scores was small, we cannot deduce that our logarithmic model will fit any individual's functional recovery at any stage after SCI. Further research is necessary to improve our model.

\section{Conclusion}

We describe a logarithmic model to predict changes in the SCIM III score, with demonstration of its clinical validity. Although the model itself does not represent any one individual's recovery, it can be used to predict expected SCIM scores at arbitrary time points. Understanding the association between treatment and recovery would further facilitate clinical decision-making throughout the rehabilitation period, including determining the ideal LOS for an individual patient.

\section{Data archiving}

All data generated or analysed during this study are included in this published article and its supplementary information file.

Funding This work was supported by a JSPS Grant-in-Aid for Scientific Research C (grant no. 15K01407 to OU).

Author contributions OU designed the study. YT and RI performed data collection and analysis. OU, YT, and ML prepared the manuscript.

\section{Compliance with ethical standards}

Statement of ethics The protocol was reviewed and approved by our hospital's research ethics committee. We certify that all applicable institutional and governmental regulations concerning the ethical use of human participants in research were followed.

Conflict of interest The authors declare that they have no conflict of interest.

Publisher's note: Springer Nature remains neutral with regard to jurisdictional claims in published maps and institutional affiliations.

\section{References}

1. National spinal cord injury statistical center, facts and figures at a glance. Birmingham, AL: University of Alabama at Birmingham, 2018.

2. Whiteneck GG, Gassaway J, Dijkers MP, Lammertse DP, Hammond $\mathrm{F}$, Heinemann $\mathrm{AW}$, et al. Inpatient and postdischarge rehabilitation services provided in the first year after spinal cord injury: findings from the SCIRehab Study. Arch Phys Med Rehabil. 2011;92:361-8.

3. Eastwood EA, Hagglund K, Ragnarsson K, Gordon W, Marino R. Medical rehabilitation length of stay and outcomes for persons with traumatic spinal cord injury-1990-1997. Arch Phys Med Rehabil. 1999;80:1457-63.

4. Kaminski L, Cordemans V, Cernat E, M'Bra KI, Mac-Thiong JM. Predictors of functional outcomes in adults with traumatic spinal cord injury following inpatient rehabilitation: a systematic review. J Spinal Cord Med. 2017;40:282-94.

5. Sangha H, Lipson D, Foley N, Salter K, Bhogal S, Pohani G, et al. A comparison of the Barthel Index and the Functional Independence Measure as outcome measures in stroke rehabilitation: patterns of disability scale usage in clinical trials. Int J Rehabil Res. 2005;28:135-9.

6. Gresham GE, Labi ML, Dittmar SS, Hicks JT, Joyce SZ, Stehlik MA. The Quadriplegia Index of Function (QIF): sensitivity and reliability demonstrated in a study of thirty quadriplegic patients. Paraplegia. 1986;24:38-44.

7. Yavuz N, Tezyürek M, Akyüz M. A comparison of two functional tests in quadriplegia: the Quadriplegia Index of Function and the Functional Independence Measure. Spinal Cord. 1998;36:832-7. 
8. Field-Fote EC, Fluet GG, Schafer SD, et al. The Spinal Cord Injury Functional Ambulation Inventory (SCI-FAI). J Rehabil Med. 2001;33:177-81.

9. Ditunno JF, Scivoletto G, Patrick M, Biering-Sorensen F, Abel R, Marino R. Validation of the Walking Index for Spinal Cord Injury in a US and European clinical population. Spinal Cord. 2008;46:181-8.

10. Catz A, Itzkovich M, Tesio L, et al. A multicenter international study on the Spinal Cord Independence Measure, version III: Rasch psychometric validation. Spinal Cord. 2007;45:275-91.

11. Anderson K, Aito S, Atkins M, Biering-Sørensen F, Charlifue S, Curt A, et al. Functional recovery measures for spinal cord injury: an evidence-based review for clinical practice and research. J Spinal Cord Med. 2008;31:133-44.

12. Hadley MN, Walters BC, Aarabi B, Dhall SS, Gelb DE, Hurlbert $\mathrm{RJ}$, et al. Clinical assessment following acute cervical spinal cord injury. Neurosurgery. 2013;72:40-53.

13. Koyama T, Matsumoto K, Okuno T, Domen K. A new method for predicting functional recovery of stroke patients with hemiplegia: logarithmic modeling. Clin Rehabil. 2005;19:779-89.

14. McLean RA, Sanders WL, Stroup WW. A unified approach to mixed linear models. Am Stat. 1991;45:54-64.

15. Bland JM, Altman DG. Statistical methods for assessing agreement between two methods of clinical measurement. Lancet. 1986;1:307-10.

16. $\mathrm{R}$ Core Team. $\mathrm{R}$ : a language and environment for statistical computing. Vienna, Austria: R Foundation for Statistical Computing; 2013.

17. Wirth B, van Hedel HJA, Kometer B, Dietz V, Curt A. Changes in activity after a complete spinal cord injury as measured by the spinal cord independence measure II (SCIM II). Neurorehabil Neural Repair. 2008;22:145-53.

18. Middleton JW, Truman G, Geraghty T. Neurological level effect on the discharge functional status of spinal cord injured person after rehabilitation. Arch Phys Med Rehabil. 1998;79:1428-32.

19. Aidinoff E, Front L, Itzkovich M, Bluvshtein V, Gelernter I, Hart $\mathrm{J}$, et al. Expected spinal cord independence measure, third version, scores for various neurological levels after complete spinal cord lesions. Spinal Cord. 2011;49:893-6.

20. Wirz M, Dietz V. Recovery of sensorimotor function and activities of daily living after cervical spinal cord injury: influence of age. J Neurotrauma. 2015;32:194-9.

21. Velstra M, Bolliger M, Krebs J, Rietman JS, Cure A. Predictive value of upper limb muscles and grasp patterns on functional outcome in cervical spinal cord injury. Neurorehabil Neural Repair. 2016;30:295-306.
22. Kaminski L, Cordemans V, Cemat E, M'Bra KI, Mac-Thiong JM. Functional outcome prediction after traumatic spinal cord injury based on acute clinical factors. J Neurotrauma. 2017;34:2027-33.

23. Denis AR, Feldman D, Thompson C, Mac-Thiong JM. Prediction of functional recovery 6 months following traumatic spinal cord injury during acute care hospitalization. J Spinal Cord Med. 2018;41:309-17.

24. van Middendorp JJ, Hosman AJ, Donders AR, Pouw MH, Ditunno FJ, Curt A, et al. A clinical prediction rule for ambulation outcomes after traumatic spinal cord injury: a longitudinal cohort study. Lancet. 2011;377:1004-10.

25. Scivoletto G, Pavese C, Bachman LM, Schubert M, Curt A, Agro $\mathrm{EF}$, et al. Prediction of bladder outcomes after ischemic spinal cord injury: A longitudal cohort study from European multicenter study about spinal cord injury. Neurourol Urodyn. 2018;37: 1779-84.

26. Catz A, Itzkovich M, Agranov E, Ring H, Tamir A. SCIM-spinal cord independence measure: a new disability scale for patients with spinal cord lesions. Spinal Cord. 1997;35:850-6.

27. Turner-Stokes L, Vanderstay R, Stevermuer T, Simmonds F, Khan F, Eagar K. Comparison of rehabilitation outcomes for long term neurological conditions: a cohort analysis of the Australian Rehabilitation Outcomes Centre Data set for adults of working age. PLoS ONE. 2015. https://doi.org/10.1371/journal.pone. 0132275 .

28. Jang HJ, Park J, Shin HI. Length of hospital stay in patients with spinal cord injury. Ann Rehabil Med. 2011;35:798-806.

29. Claydon VE, Steeve JD, Krassioukov A. Orthostatic hypotension following spinal cord injury: understanding clinical pathology. Spinal Cord. 2006;44:341-51.

30. Sidrov EV, Townson AF, Dvorak MF, Kwon BK, Steeves J, Krassioukov A. Orthostatic hypotension in the first month following acute spinal cord injury. Spinal Cord. 2008;46:65-9.

31. Krassioukov A, Dng JJ, Warburton DE, Teasell R. Spinal cord injury rehabilitation evidence research team. A systematic review of the management of orthostatic hypotension after spinal cord injury. Arch Phys Med Rehabil. 2009;90:876-85.

32. National spinal cord injury database. http://www.kibirihah.johas. go.jp/003_reha/10_sekison_db.html. Accessed 23 Dec 2018.

33. Wyndaele M, Wyndaele JJ. Incidence, prevalence and epidemiology of spinal cord injury: what learns a worldwide literature survey? Spinal Cord. 2006;44:523-9.

34. Chan WM, Mohammed Y, Lee I, Pearse DD. Effect of gender on recovery after spinal cord injury. Transl Stroke Res. 2013;4: $447-61$. 